\title{
Increasing Family Medicine Faculty Diversity Still Lags Population Trends
}

\author{
Imam M. Xierali, PhD, Marc A. Nivet, EdD, MBA, Anne H. Gaglioti, MD, \\ Winston R. Liaw, MD, MPH, and Andrew W. Bazemore, MD, MPH
}

Background: Faculty diversity has important implications for medical student diversity. The purpose of this analysis is to describe trends in racial, ethnic, and gender diversity in family medicine (FM) departments and compare these trends to the diversity of matriculating medical students, the diversity of all medical school faculty, and the population in general.

Methods: We used the Association of American Medical Colleges Faculty Roster to describe trends in proportions of female and minorities under-represented in medicine (URM) in FM department full-time faculty in U.S. MD-granting medical schools.

Results: Among FM faculty, the proportions of female and URM faculty have grown more than 2-fold between 1980 and 2015. Increasing faculty rank was associated with lower diversity across the study period. FM departments had higher female and URM proportions than the average of all other specialties, but URM representation still lagged population trends.

Conclusion: Although FM faculty diversity is growing over time, continued attention to URM representation should remain a priority. (J Am Board Fam Med 2017;30:100-103.)

Keywords: Ethnic Groups, Medical Faculty, Minority Groups, Medical Schools, Medical Students

Medical school faculty diversity has been linked to medical student diversity, the cultural competence of medical graduates, and the cultural climate of medical school campuses. ${ }^{1,2}$ A higher percentage of minority than white students reported that faculty diversity was a "positive" or "very positive" factor in selecting a medical school. ${ }^{3}$ However, medical school faculty diversity has not kept pace with the diversity of medical school students or of the rest of society. In this brief report, we review trends in racial, ethnic, and gender diversity in FM departments from 1980 to 2015 and compare these trends

This article was externally peer reviewed.

Submitted 29 June 2016; revised 31 August 2016; accepted 6 September 2016.

From the Association of American Medical Colleges, Washington, DC (IMX); University of Texas Southwestern Medical Center, Dallas, TX (MAN); National Center for Primary Care, Department of Family Medicine, Morehouse School of Medicine, Atlanta, GA (AHG); Robert Graham Center for Policy Studies in Family Medicine and Primary Care, Washington, DC (WRL, AWB).

Funding: none.

Conflict of interest: none declared.

Corresponding author: Imam M. Xierali, $\mathrm{PhD}$, Association of American Medical Colleges, 655 K St. NW, Suite 100; Washington, DC 20001-2399 (E-mail: ixierali@aamc.org). to the diversity of matriculating medical students, the diversity of all medical school faculty, and the population in general.

\section{Methods}

We used data from the Association of American Medical Colleges (AAMC) Faculty Roster, a comprehensive national database of U.S. medical school faculty, to describe sex, race, and ethnicity trends of FM department faculty in U.S. MDgranting medical schools. These data were obtained through the Faculty Administrative Management On-line User System (FAMOUS). ${ }^{4}$ The AAMC initiated the Faculty Roster in 1966 and collects comprehensive information on the characteristics of full-time faculty members at accredited allopathic U.S. medical schools. We calculated proportions of female and racial and ethnic minorities underrepresented in medicine (URM) by faculty rank for both FM and all other departments. We defined URM as Hispanic (of any race), nonHispanic black/African American, non-Hispanic American Indian/Alaska Natives, and non-Hispanic Native Hawaiian/Pacific Islanders. We then com- 
Figure 1. Female and underrepresented minority (URM) proportions, 1980 to 2015. Data source: Association of American Medical Colleges Faculty Roster, December 31 Snapshots.

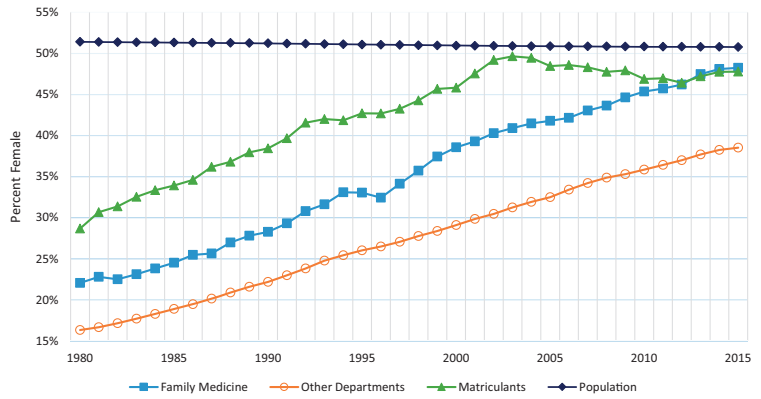

pared faculty diversity to U.S. population diversity and medical school matriculating student diversity as reported in the AAMC Applicant and Matriculant Biographic File from 1980 to 2015. The American Institutes for Research institutional review board deemed this project as exempt.

\section{Results}

The last 3 decades saw significant growth in faculty size and diversity in academic FM departments and in other academic departments. Nationally, the number of FM department full-time faculty grew nearly 4-fold from 1396 in 1980 to 5507 in 2015. Female and URM proportions in FM faculty also grew more than 2-fold over the time period (Figure 1). However, 3 distinct patterns emerged. First, confirming earlier findings, ${ }^{5}$ lower rank professoriates remained more diverse than those in higher ranks for both FM and all other departments (Figure 2). Second, FM departments had higher proportions of female and URM than all other department faculty as a group. Third, although there was historic progress, the proportion of faculty that

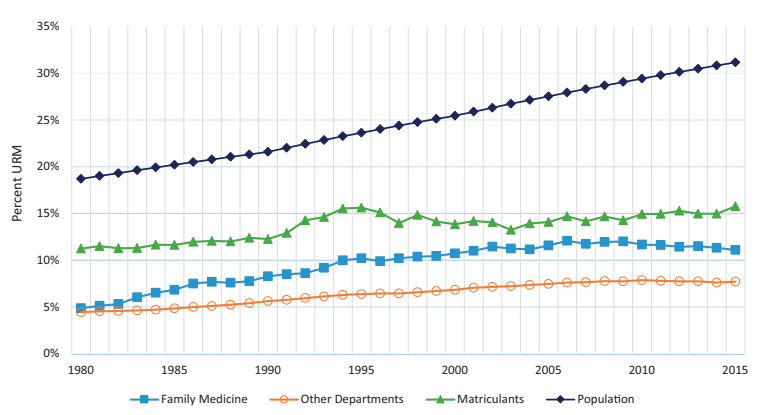

were URM remained below that of matriculating medical students and the U.S. population for both FM and other departments' faculty. Although FM faculty closed the female gap with matriculating medical students albeit not with the general population, the gender gap remained much wider for faculty from other departments combined. Furthermore, female faculty proportions had faster growth in both FM departments and all other departments as a group when compared with URM faculty proportions. In 2015, the females made up $51 \%$ of FM assistant professors, whereas the URMs accounted for $12.6 \%$ of this group. This was less than half of the URM proportion (estimated to be $31.2 \%)$ of the U.S. population in 2015.

\section{Discussion}

Faculty diversity has grown but still neither reflects the diversity of the U.S. population nor that of medical students. The fact that lower-rank professoriates had higher proportions of female and URM faculty than higher rank professoriates highlights the mobility barriers these groups face from

Figure 2. FM department faculty female and underrepresented minority (URM) proportions by rank (excluding instructors and faculty with "other" ranks). Data source: Association of American Medical Colleges Faculty Roster, December 31 Snapshots.
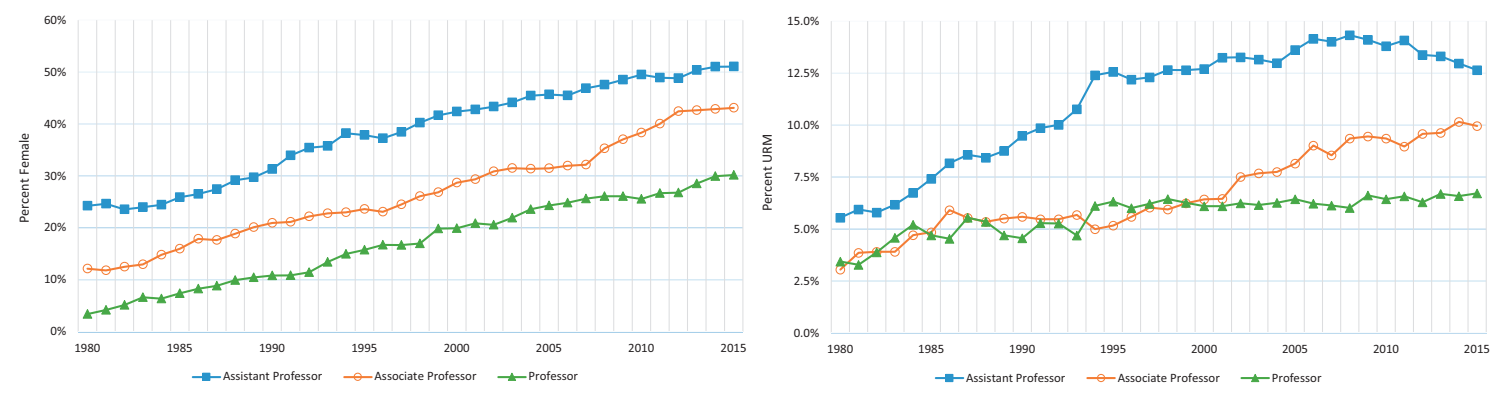
a promotion perspective. ${ }^{6,7}$ Though the specific barriers would need to be elucidated in future studies, we hypothesize that they may include overt prejudice, subtle discrimination, undervaluing the unique contributions of women and URMs, family responsibilities, and opting out of promotion paths. Early studies have found that female and nonwhite faculty members had lower promotion rates and leave full-time faculty appointments at a higher rate than male and white faculty members. ${ }^{5,8,9}$ The tendency for URM and female physicians to practice primary care could partially explain higher FM department faculty diversity compared with other departments. ${ }^{10,11}$ The fact that FM departments are becoming more diverse is encouraging, given that primary care faculty are charged with training the source of first contact, continuous, coordinated, and comprehensive care for underserved minority patients. $^{12}$

There are several limitations in this study. First, Faculty Roster data were reported by medical schools. We could not confirm whether faculty gender, race, and ethnicity were completely self reported. Second, our unit of analysis is medical school department based on a December 31 snapshot for each calendar year. There were 128 departments across 121 medical schools classified as FM department as of December 31, 2015. We reported diversity by departments, not by physician's specialties. For instance, there could be a faculty with a MD degree in FM serving in another department. Moreover, not all faculty are necessarily physicians. In $2015,80.4 \%$ of full-time faculty at FM departments held a MD degree. Non-physician faculty diversity may reflect more of the current diversity challenges in the overall biomedical research workforce in the nation. ${ }^{13}$ We were unable to differentiate International Medical Graduate (IMG) status of faculty in this study. Understanding how IMG faculty self identify regarding race and ethnicity is an important research question to be examined. Furthermore, we combined all other department faculty as a single group for reference. This masks the substantial interdepartmental variations in diversity by gender, race, and ethnicity. For instance, female and URM proportions for FM departments in 2015 were ranked 10th and seventh out of all 36 academic departments (based on medical school department classification). Finally, our analysis does not establish a causal relationship between faculty diversity and student di- versity, although strong associations have been demonstrated. ${ }^{14}$ Earlier findings suggest that diversity would be slower for faculty as their turnover is much longer than medical students. This seems to suggest that student diversity improvement would eventually lead to faculty diversity improvement in the long run.

Better approaches are needed to improve faculty diversity and opportunities for promotion of diverse faculty in academic medicine overall and in FM faculty. Pipeline programs for academic FM departments should be strengthened and initiated at an early stage of training. ${ }^{15}$ Mentoring minority and female junior faculty members in academic FM is also important. Finally, medical schools and academic FM departments may need to review their current practices and policies with an eye toward enabling more faculty diversity through institutional transformation ${ }^{7}$ and moving diversity from the periphery to the core of institutional excellence. ${ }^{16}$

The authors thank for the careful review of the early draft by Ms. Rae Anne Sloane, Faculty Roster Coordinator, at the AAMC.

To see this article online, please go to: http://jabfm.org/content/ 30/1/100.full.

\section{References}

1. Nunez-Smith M, Ciarleglio MM, Sandoval-Schaefer $\mathrm{T}$, et al. Institutional variation in the promotion of racial/ethnic minority faculty at U.S. medical schools. Am J Public Health 2012;102:852-8.

2. Xierali IM, Fair MA, Nivet MA. Faculty diversity in U.S. medical schools: Progress and gaps co-exist. AAMC Anal Brief 2016;16(6).

3. Zhang K, Xierali I, Castillo-Page L, Nivet M, Schoolcraft Conrad S. Students' top factors in selecting medical schools. Acad Med 2015;90:693.

4. Association of American Medical Colleges. Faculty Roster: U.S. Medical School Faculty, 1980 through 2015. Available from: https://services.aamc.org/ famous/. Accessed March 18, 2016.

5. Liu CQ, Alexander H. The changing demographics of full-time U.S. medical school faculty, 1966-2009. AAMC Anal Brief 2011;11(8).

6. Fang D, Moy E, Colburn L, Hurley J. Racial and ethnic disparities in faculty promotion in academic medicine. JAMA 2000;284:1085-92.

7. Alexander H, Lang J. Long-term retention and attrition of U.S. medical school faculty. AAMC Anal Brief 2008;8(4).

8. Liu CQ, Alexander H. Promotion rates for first-time assistant and associate professors appointed from 1967 to 1997. AAMC Anal Brief 2010;9(7). 
9. Yamagata H. Trends in faculty attrition at U.S. medical schools. AAMC Anal Brief 2002;2(2).

10. Xierali IM, Nivet MA, Fair MA. Analyzing physician workforce racial and ethnic composition associations (part-1): Physician specialties. AAMC Anal Brief 2014;14(8).

11. Xierali IM, Castillo-Page L, Conrad S, Nivet MA. Analyzing physician workforce racial and ethnic composition associations (part-2): Geographic distribution. AAMC Anal Brief 2014;14(9).

12. Starfield B, Shi L, Macinko J. Contribution of primary care to health systems and health. The Milbank Quarterly 2005;83:457-502.

13. Gibbs KD Jr, Basson J, Xierali IM, Broniatowski D (2016). Decoupling of the minority PhD talent pool and assistant professor hiring in medical school basic science departments in the US. eLife 2016. DOI:
10.7554/eLife.21393. Available at https://elifesciences. org/content/5/e21393.

14. Mader EM, Rodriguez JE, Campbell KM, Smilnak T, Bazemore AW, Petterson S, Morley CP. Status of underrepresented minority and female faculty at medical schools located within historically black colleges and in Puerto Rico. Med Educ Online 2016; 21:29535.

15. Association of American Medical Colleges. Striving Towards Excellecence: Faculty Diversity in Medical Education. 2009. Available from: http://members.aamc. org/iweb/upload/09-003\%20Benefits\%20of\%20 Faculty\%20Diversity_DDPP\%203\%2025\%2038\% 20PM.pdf. Accessed June 27, 2016.

16. Nivet MA. Commentary: Diversity 3.0: A necessary systems upgrade. Acad Med 2011;86:1487-9. 